\title{
UNA NUEVA ESPECIE DE SERPOPHAGA (AVES: TYRANNIDAE)
}

\author{
STRANECK, R. ${ }^{1}$
}

\begin{abstract}
RESUMEN
Berlioz (1959) crea a Serpophaga griseiceps sobre 4 ejemplares de Chochabamba, Boliva, luego Traylor (1982) dice que estos ejemplares son juveniles de Serpophaga munda, mas adelante van Remsen y Traylor (1988) ratifican esto. Straneck (1993), unifica a Serpophaga subcristata con Serpophaga munda por tener iguales repertorios acústicos, y diferencia a otra Serpophaga de estas dos por que su repertorio acústico, que es completamente diferente al de éstas, además de ser en promedio un centímetro mas corta y tener muy poco blanco o no tener nada de blanca en la corona. Al coincidir el color del plumaje, con la especie descripta por Berlioz (1959), fue considerada conespecífica con ésta. Luego Herzog y Mazar Barnett (2004), vuelven a invalidar a Serpophaga griseiceps, regresándola a la sinonimia de Serpophaga munda. Pero hacen esto sin evaluar y comparar el repertorio acústico ni el largo total de esta especie con Serpophaga s. subcristata. Por lo tanto como no tenemos material acústico que acompañe los ejemplares de Berlioz, como para compararlo con la especie que nos ocupa. Y ante el hecho que esta Serpophaga es más pequeña que $S$. s. subcristata $\mathrm{y}$ tiene un repertorio vocal diferente la describimos como una especie nueva.

Palabras clave: Una nueva especie de Serpophaga.
\end{abstract}

1.- División Ornitología Museo Argentino de Ciencias Naturales "Bernardino Rivadavia”. Av. A. Gallardo 470. C1405DJR Buenos Aires, Argentina

Manuscrito recibido el 22 de junio de 2007 y aceptado para su publicación el 13 de septiembre de 2007. 